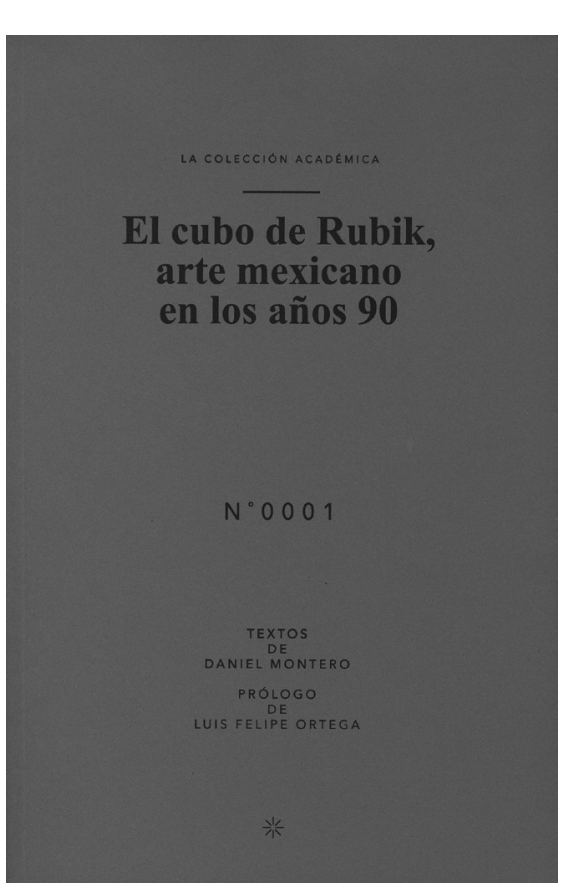

FIGURA 1. Portada del libro El cubo de Rubik, arte mexicano en los años 90, de Daniel Montero, México, Fundación Jumex Arte Contemporáneo + RM, Colección Académica, 1, 2014.

\section{El cubo de Rubik, arte mexicano en los años 90, de Daniel Montero}

\author{
Rubik's Cube, Mexican Art in the 90s, by Daniel Montero
}

\section{Gabriela A. Piñero}

Universidad de Buenos Aires (UBA),

Universidad Nacional del Centro de la Provincia de Buenos Aires (Unicen), Argentina pinero.gabriela@gmail.com

\section{Resumen}

¿Cómo dar cuenta de la diversidad de factores que, en el México de los años noventa, determinó el desplazamiento de una manera de hacer arte que se llamó neomexicanismo a otra vinculada con el arte-objeto-conceptual? ¿De qué modo se articularía esta nueva modalidad artística con el progresivo abandono de marcos de sentido nacionales, a favor de relatos que ya no buscaban inscribir las obras en el terreno de lo geográfico, sino en el horizonte de lo contemporáneo?

El cubo de Rubik. Arte mexicano en los años noventa, de Daniel Montero (2014), analiza de qué manera se concatenaron varios fenómenos ocurridos en la escena artística mexicana para transformar el campo local del arte a partir de la redefinición tanto de lo artístico como de las formas de producción plástica y narrativa. Los diversos frentes que analiza Montero (los múltiples lados del cubo de Rubik) esbozan la configuración de una zona en la que lo artístico es también política y economía.

\section{Palabras clave}

arte contemporáneo; historia; crítica de arte; México

\section{Abstract}

How to present the diversity of factors that, in the Mexico of the 90s, determined the displacement of a way to create art called neomexicanismo to another linked to object-conceptual-art? How was this new artistic modality articulated with the progressive neglect of frameworks with a national meaning, in favor of narratives that no longer sought to be geographically relevant, but that prioritized the contemporary?

Rubik's cube. Mexican art in the 90s by Daniel Montero (2014), analyzes the way in which different events that took place in the Mexican art scene came together to transform the local art field, departing from the redefinition of both art and the plastic and narrative production forms. The different approaches analyzed by Montero (the different sides of the Rubik's cube) present the configuration of an area in which art is also politics and economy. 


\section{Key words}

contemporary art; history; art critique; Mexico

- Cómo dar cuenta de la diversidad de factores que, en el México de la década de 1990, transformó la manera de producir arte para pasar del neomexicanismo ${ }^{1}$ al arte-objetoconceptual? ¿De qué modo esta nueva forma artística habría de indicar el desplazamiento de marcos de sentido nacionales a obras y relatos que ya no buscaron inscribirse (tanto) en el terreno de lo geográfico sino, más bien, anclarse en el horizonte de lo contemporáneo? ¿Cómo pensar y escribir las interrelaciones que en esta tarea operaron desde la crítica, la curaduría, la producción e incluso el mercado?

Desde la historia institucional y la sociología del arte, El cubo de Rubik. Arte mexicano en los años noventa, de Daniel Montero (2014), analiza cómo, a partir de una redefinición de lo artístico y de las formas de producción plástica y narrativa, una serie de fenómenos ocurridos en la escena artística mexicana de los años noventa se articuló de modo tal que transformó el campo local del arte. El estudio de los procesos de institucionalización de un conjunto de producciones que, durante el periodo analizado por Montero: 1988-2007, se corrieron de la alternatividad al terreno del arte contemporáneo (la institucionalidad) enfatiza el valor móvil de las obras y de sus horizontes de sentido (Montero 2014:151, 24). Los conceptos de capital cultural y capital simbólico, tomados de Pie-

\footnotetext{
${ }^{1}$ El término nuevos mexicanismos fue acuñado por la crítica e historiadora del arte mexicana Teresa del Conde en 1987. Con éste se refería a un grupo de pintores cuya obra adquirió gran visibilidad en la década de 1980: Enrique Guzmán, Adolfo Patiño, Carla Rippey, Javier de la Garza, Eloy Tarcisio, Nahum B. Zenil, entre otros: en sus producciones aparecían, por medio de la recuperación de códigos e imágenes persistentes propias de la cultural local, "ciertas constantes de identidad dispersas" (Conde 1987: s. p.; Debroise 2006b:276278).
}

rre Bourdieu, estructuran los diversos capítulos del libro (los múltiples lados del cubo de Rubik) y esbozan la configuración de una zona en que lo artístico es también política y economía.

Con un prólogo del artista Luis Felipe Ortega, ${ }^{2}$ El cubo de Rubik apuesta, mediante el ensayo, a posicionarse en la serie de debates que acompañó la visibilidad y la comercialización creciente de artistas como Gabriel Orozco (México), Teresa Margolles (México), Francis Alÿs (Bélgica), Rubén Ortiz Torres (México) y el propio Ortega (México), por mencionar algunos. El primer capítulo del libro, "Obelisco roto para mercados ambulantes", analiza el devenir del Obelisco roto portátil para mercados ambulantes, de 1992, obra de Eduardo Abaroa (Debroise 2006a), e informa del carácter y el proceso de institucionalización del nuevo arte. Hecho con lona color rosa mexicano que se tensa en una estructura de hierro desarmable, Obelisco roto es una "versión chaparra" del Broken Obelisk (1963-1969) de Barnett Newman (MOMA 2016). Exhibido por primera vez en Temístocles 44 - uno de los tantos espacios alternativos que proliferaron a fines de los años ochenta en México-, así como junto al tianguis de Santo Domingo, al sur de la Ciudad de México, y posteriormente en Guadalajara (México), Nueva York (EUA) y el Palacio de Bellas Artes (PBA, Ciudad de México) del Instituto Nacional de Bellas Artes (INBA), la obra refleja una alternatividad que, ya a inicios del año 2000, se erigía como nuevo canon del arte hecho en el país (Montero 2014:29, 43, 153-154).

\footnotetext{
2 Luis Felipe Ortega (Ciudad de México, 1966), egresado de la Facultad de Filosofía y Letras de la Universidad Nacional Autónoma de México (FFYL-UNAM), es parte del grupo de artistas que renovó la práctica artística en la década de 1990. Su obra se despliega en diversos soportes, incluido el dibujo, el video, la fotografía, la escultura y la instalación. Participó en numerosas exposiciones en México y el extranjero; en 2015 representó a México en la 56 Bienal de Venecia (Ortega 2014).
}

La hipótesis que recorre por completo el libro plantea que la liberación de capitales de todo tipo en un contexto neoliberal de globalización hace difícil pensar en una posible diferencia radical en términos de disidencia militante. El cambio en las políticas económicas que regulaban el país con el fin de ingresar en el "mundo globalizado" —mediante, por ejemplo, la firma del Tratado de Libre Comercio de América del Norte (TLCAN 1994) - aparece en el relato de Montero como intrínseco a los desplazamientos experimentados en las formas de producir y escribir el arte local. De esta hipótesis se sirve el autor para, asimismo, resaltar el modo en que la apertura a los capitales privados (locales y foráneos) cambió - o al menos hizo que se diversificaran- los lugares tradicionales de promoción de dicho arte. De este modo, junto a aquéllos, empezaron a circular en el país capitales simbólicos inéditos.

El análisis emprendido en el segundo capítulo, "Capitales culturales-capitales económicos", borda sobre esta estrecha vinculación entre economía y cultura en un contexto globalizado, y revela cómo el "éxito" económico relativamente alcanzado por este conjunto de producciones de los noventa se dio luego del intento frustrado por comercializar en el exterior el neomexicanismo, y a causa del giro hacia obras más "conceptuales" que, principalmente por la recesión económica de 1990-1991, estaba experimentando el mercado del arte internacional (Montero 2014:58-59). En la escena local, esta nueva dirección resulta evidente en el "ajuste" que hicieron a su planta de artistas galerías como la OMR (1983) y Arena México (mediados de los años noventa), que de promocionar obras "neomexicanistas" se decantaron por otro tipo de piezas más "conceptuales". La argumentación de Montero se construye, así, con base en el diálogo entre una escena artística mexicana que conoce muy bien y una serie de reflexiones más generales sobre la naturaleza y 
el funcionamiento tanto del mercado artístico internacional como de ciertas políticas, vigentes primordialmente en Estados Unidos de América, de representación y circulación.

Por medio de una serie de entrevistas exhaustivas a artistas, curadores, coleccionistas, directores de museos, críticos y otros agentes activos en el periodo analizado, Montero recupera el modo en que las nuevas prácticas que emergieron a fines de los ochenta y durante los noventa buscaron modificar ciertas lógicas institucionales, más que permanecer en sus bordes. Junto al estudio sobre el efecto de los nuevos capitales privados antes referido, Montero analiza el papel del Estado en la producción y la promoción del nuevo arte. La fundación, en 1988, del Consejo Nacional para la Cultura y las Artes (Conaculta) y del Fondo Nacional para la Cultura y las Artes (Fonca) - hechos que marcan el inicio del periodo abordado por Montero- posibilitó, y aun alentó, estas prácticas y sus espacios a través de sus políticas de financiamiento. Como señala el autor, aportar dinero para proyectos artísticos (y no para obras en curso) implicó una redefinición de lo artístico en términos de proceso (no de producto). La dinámica del Fonca, que estipulaba la discusión, junto con la comisión consultiva, del proceso creativo a lo largo de un año, evidencia, por otra parte, la importancia que la reflexión teórica adquirió en la práctica artística durante estos años, no sólo en México. José Miguel González Casanova, uno de los fundadores de Temístocles 44, relata que la instauración de estos espacios respondió también al interés por fomentar tanto el despliegue del pensamiento crítico como parte inherente a la práctica artística, como una discusión sobre los procesos creativos, ausente en las escuelas de arte de aquel momento (Montero 2014:119). ${ }^{3}$ El tercer $y$ el cuarto capítulos, "Reformulando

${ }^{3}$ José Miguel González Casanova (Ciudad de México, 1964) trabaja en el cruce de disciplinas diversas y gran parte de sus proyectos — muchos de ellos autogestionados — reflexio- la pregunta por la alternatividad" y "De curadores, críticos y directores", abordan estos aspectos a detalle, al analizar los diversos procesos de institucionalización de dichas prácticas y la función que desempeñaron los nuevos relatos críticos, curatoriales y museográficos.

Si la periodización establecida por Montero arranca, como ya he dicho, en 1988 con la fundación del Conaculta y el Fonca, debido al papel que sus políticas culturales desempeñaron en el proceso de institucionalización del nuevo arte, se cierra en 2007, año en que se montó la exhibición La era de la discrepancia. Arte y cultura visual en México 1968-1997, en el Museo Universitario de Ciencias y Artes (MUCA) de la Universidad Nacional Autónoma de México (UNAM). Con la incorporación de la obra de Abaroa a esta exposición finaliza el análisis de Montero del devenir del Obelisco roto, esto es, los procesos de institucionalización estudiados concluyen con esta operación que el autor lee en términos de patrimonialización de la diferencia. Desde la exposición del 2007 esta obra, que es propiedad de Patrick Charpenel, forma parte de las colecciones asociadas al Museo Universitario de Arte Contemporáneo (MUAC-UNAM), el primero de arte contemporáneo del país (Montero 2014:252). Con La era de la discrepancia, por otra parte, se inauguraba una tradición de arte disidente, fuertemente cuestionador de las instituciones y de las formas de hacer arte instituidas. El análisis de los relatos críticos y curatoriales le permitió a Montero, adicionalmente, revisar la forma en que la necesidad de las nuevas producciones de argumentar la actualidad exigió también

na sobre el espacio público y la educación artística. Esta promoción de la "autocrítica, el intercambio de ideas y la discusión acerca de los procesos artísticos por medio de la documentación y exhibición de los procesos de producción de las obras" signó también las actividades de Temístocles 44, espacio fundado por González Casanova junto con otros jóvenes artistas en 1993 (Macías 2006:367). una reescritura de las genealogías del arte, no sólo mexicano. El último capítulo, "La globalización como problema", trata, en esta dirección, de las particulares negociaciones que se dieron entre contextos de producción locales y debates que progresivamente asumían la globalización, el descentramiento y la deslocalización como horizontes de sentido de las prácticas.

La crisis del concepto de identidad que se manifiesta, no únicamente en México, en gran cantidad de obras del periodo es, en parte, la crisis de una representación nacional administrada por el Estado, visible en el grupo de obras pertenecientes a los noventa que analiza Montero, por la manera heterodoxa en que se apropian de lo propio y de lo ajeno y reformulan las tradiciones no solamente artísticas. En este sentido, el autor examina una serie de textos críticos en los cuales el nuevo arte, en general, y Obelisco roto, en particular, ya no se presentaban en continuidad con la tradición escultórica mexicana sino que ambos referentes - lo escultórico y lo mexicano- aparecían desplazados para inaugurar un nuevo arte, inserto en el territorio de lo globalizado. El Obelisco roto de Abaroa reconoce un doble modelo: el Broken Obelisk de Newman, por un lado, y la carpa de mercado ambulante, por el otro; ambos son, a la vez, ajenos y propios. El Broken Obelisk de Newman es externo a la tradición artística mexicana, pero propio en cuanto obra legitimada del campo del arte. De manera análoga, si bien la carpa de mercado es un referente típicamente mexicano, es un elemento ajeno al mundo del arte. En el México de los noventa, lo contemporáneo se fundó, así, a partir de un singular diálogo con lo local, pero entablado, asimismo, con una globalidad.

El cubo de Rubik es el primer título del programa editorial de la Fundación Jumex, manifestación de la diversificación de lugares interesados en construir y escribir la historia. Resultado de la investigación doc- 
toral de Daniel Montero, este libro viene a salvar la escasez de publicaciones sobre el arte reciente de México: como lo señala en la introducción, su objeto fue presentar amplia y razonadamente una serie de problemas (por ejemplo, la incorporación de la industria privada en la producción y la promoción del arte) que hasta entonces no se habían discutido sino apenas de manera fragmentada en algunas publicaciones y catálogos de exposición. El único libro que había tratado de ofrecer un relato unificado sobre el arte hecho en México durante los años noventa, New Tendencies in Mexican Art: The 1990s, de Rubén Gallo (2004), fue objeto de una fuerte controversia (Montero 2014:240-241). Los alcances de El cubo de Rubik. Arte mexicano en los años noventa, no se limitan, sin embargo, a ese ámbito, pues introduce reflexiones que, surgidas de una contemporaneidad cada vez más globalizada, nos interpelan y permiten reflexionar, de manera comparativa, sobre las singularidades de diversas escenas locales. ${ }^{4}$

\footnotetext{
${ }^{4}$ Agradezco a los revisores y editores de esta reseña por sus lúcidas observaciones y sugerencias.
}

\section{Referencias}

\section{Arena México}

2016 Arena México. Arte Contemporáneo [página web], México, documento electrónico disponible en [http://arenamexico.format.com/3579875-about], consultado en octubre de 2016.

Conde, Teresa del

1987 "Nuevos mexicanismos", Uno más Uno, México, s. p.

Debroise, Olivier 2006a "Remakes", en Olivier Debroise (ed.), La era de la discrepancia. Arte y cultura visual en México 1968-1997, México, MUCA-UNAM, 407.

2006b "Me quiero morir", en Olivier Debroise (ed.), La era de la discrepancia. Arte y cultura visual en MéxiCo 1968-1997, México, MUCA-UNAM, 276-278.

Gallo, Rubén

2004 New Tendencies in Mexican Art: The 1990s, New York, Palgrave Macmillan.

Macías, Vania

2006 "Espacios alternativos de los noventa", en Olivier Debroise (ed.), La era de la discrepancia. Arte y cultura visual en México 1968-1997, México, MUCA-UNAM, 366-370.
MOMA

2016 "Broken Obelisk de Barnett Newman 1963-1969" [página web], EUA, MOMA, documento electrónico disponible en [https://www.moma.org/co llection/works/81555], consultado en octubre de 2016.

Montero, Daniel

2014 El cubo de Rubik. Arte mexicano en los años noventa, México, Fundación Jumex Arte Contemporáneo + RM, Colección Académica, 1.

OMR

2015 Galería OMR [página web], México, documento electrónico disponible en [http://galleryweekendmexico. com/galeria-omr-2015], consultado en octubre de 2016.

Ortega, Luis Felipe

2014 Luis Felipe Ortega [página web], documento electrónico disponible en [http://www.luisfelipeortega.com], consultado en noviembre de 2016.

TLCAN

1994 Tratado de Libre Comercio de América del Norte [página web], documento electrónico disponible en [http://www.tlcanhoy.org/faq_es. asp\#faq-1], consultado en octubre de 2016. 


\section{Gabriela A. Piñero}

Universidad de Buenos Aires (UBA),

Universidad del Centro de la Provincia de Buenos Aires (Unicen)

pinero.gabriela@gmail.com

Doctora en historia del arte (Universidad Nacional Autónoma de México [UNAM], México), magíster en historia del arte en la misma institución y licenciada en Artes (Universidad de Buenos Aires [UBA], Argentina). Fue becaria posdoctoral del Consejo Nacional de Investigaciones Científicas y Técnicas [Conicet], Argentina, y docente en la Facultad de Artes de la Universidad Nacional del
Centro de la Provincia de Buenos Aires ([Unicen] Argentina), y en la Escuela de Bellas Artes Luciano Fortabat de la Ciudad de Azul, Buenos Aires (Argentina). Especialista en teoría y crítica de arte contemporáneo en América Latina. Ha publicado su investigación y participado en congresos nacionales e internacionales en Argentina, México, Colombia, Canadá y los Estados Unidos.

Postulado/Submitted 10.03.2016

Aceptado/Accepted 01.12.2016

Publicado/Published 31.01.2016 